\title{
An Analysis of Students' Misconceptions About the Implementation of Active Learning of Optics and Photonics Approach Assisted by Computer Simulation
}

\author{
https://doi.org/10.3991/ijet.v15i09.12217 \\ Ida Kaniawati, Sri Rahmadani, Nuzulira Janeusse Fratiwi, Iyon Suyana, \\ Agus Danawan, Achmad Samsudin, Endi Suhendi $(\bowtie)$ \\ Universitas Pendidikan Indonesia, Bandung, Indonesia \\ endis@upi. edu
}

\begin{abstract}
Misconceptions take place in a variety of Physics lessons including Lights and Optics. This study aims at determining the students' misconceptions and the effectiveness of the Active Learning of Optics and Photonics (ALOP) approach assisted by computer simulation to reduce misconceptions among students about the material of optical instruments. The mixed-method was employed in this study using an embedded mixed-method design. The study was conducted on students of Grade XI in one senior high school in Bandung. The participants were divided into two groups: a control group and an experimental group in which each group consisted of 23 students. Conventional learning was applied in the control group, while the experimental class implemented the ALOP computer-aided simulation learning. The instrument used to identify the students' misconceptions were Four-Tier Optics and Photonics Test (FTOPT); it consisted of 18 items which were administered during the pre-test and post-test. The results showed that the misconceptions were disseminated over the concept of eyes, camera, magnifier, microscopes, and telescopes. Additionally, ALOP approach using computer-aided simulations was found to be effective to reduce students' misconceptions about optical instruments.
\end{abstract}

Keywords-ALOP, computer simulation, misconceptions, optical instrument material, senior high school students

\section{Introduction}

As the development of education keeps moving forward, learning has shifted from teacher-centred learning to student-centred learning. This means that students are required to be more active in acquiring knowledge. When the learning takes place, the information is processed in the brain to construct new knowledge. Since students construct their own knowledge, there is a possibility that their concept contradicts with the concept shared by the experts. The incompatibility between the students' understanding of the concept with the concept adopted by the experts is generally called misconception [1-6]. 
The misconception occurs in almost all of the matter physics topics at school including in the materials of optical instruments and it has become a problematic issue [7]. Munawaroh [8] found that misconception occurred on the topic of optical instrument. In the sub-unit material about the eyes, about $26.67 \%$ students had misconceptions about the topic, and one example was that students stated that the eye's near point of a hypermetropia sufferer is farther than the nearest point of a normal eye, so that objects that will be seen as if they are placed lower than $25 \mathrm{~cm}$ from the actual height. A total of $30.26 \%$ of the students experienced misconceptions about the subunit material about the camera; the students expressed that the pupil of the human eye has the same functionality as the diaphragm that regulates the intensity of incoming light. As much as $20.51 \%$ of the students experienced misconceptions regarding projectors, microscopes and $17.95 \%$ had misconceptions about the telescopes and as much as $35.26 \%$ had a misconception about on Loop. Students stated that the strength of the loop was not affected by the medium in which the loop was used, indicating that the strength of the loop in the air and in the water is the same.

Factors that lead to various misconceptions in physics according to Borgerding et al. [9] and Putri et al. [10] are due to students, teachers, textbooks, context, and methods of teaching. Based on a preliminary study conducted by the researchers at one high school in Bandung, physics is often taught using the lecture method. The lecture learning method determines that the main source of knowledge is a teacher and a book, apart from not implementing the experiment and learning media. Experimental activity is very important to do so that students have no difficulty observing the targeted concept, especially in a case that requires analysis, such as light and optics. Students cannot describe special rays on the formation of images using a convex lens; almost all the students from the two classes were confused and were not able to completely describe the special rays, as well as the properties of the image produced. The identification of these problems indicates that learning physics is an activity of memorizing a concept without testing the validity and confidence of the students about the concepts they have been introduced to. Therefore, knowledge does not last long and students are not sure about the concept.

Physics is the branch of science that looks at the phenomena of nature, where a phenomenon is conveyed through the use of concepts, theories, and laws of physics so that human reason can accept it [11]. Not all natural phenomena are easy to be observed and explained. Some are abstract natural phenomena, thus requiring the media to study the phenomenon. One example is the phenomenon of sight, the students found it difficult to analyse the process that occurs so that one can see and interpret the objects being seen.

Active Learning of Optics and Photonics (ALOP) is the learning that is expected to improve the efficiency and effectiveness of the achievement of learning objectives, especially in the material of optical instruments, as well as reducing student misconceptions caused by an error when constructing their own knowledge. Likewise, a literacy study conducted by Alborch et al. [12] obtained the results that the experimental class applying learning using ALOP, reached a value of $\mathrm{N}$-gain of 0.69 that was a higher category, while the $\mathrm{N}$-gain of the control class produced an $\mathrm{N}$ - gain of 
0.19 which was considered as a lower category. Alborch et al. [12] concluded that the ALOP was effective in improving students' conceptual knowledge.

Based on the learning principle above, ALOP is an instructional approach in accordance with the recent applicable curriculum in Indonesia. The advent of computer technology and a new understanding of a student's learning difficulties to build knowledge about some abstract concepts in physics, giving a boost to the researchers to create a physics lab program that is more attractive, practical and effective [13]. Computer-based learning allows students to collect, display and analyse the data that have catalyzed as laboratory-based learning design, thus enabling students to master a whole coherent concept of physics directly [14]. Observation activities on the computer simulations facilitate learning, allowing students to comprehend a concept, explore, and construct their own understanding, giving a positive effect on conceptual understanding, and effective for avoiding misconception.

Simulations are replicas or imitations of an operation of a process or a real system [15]. Computer simulations can be interpreted as an imitation of the workings of a real process that is displayed on the computer. The computer simulation enables students to observe and analyses the processes, thereby avoiding the possibility of a student of misconceptions. The fact that information technology is so advanced, there are various computer simulations used as a medium of learning, but the computer simulations invented did not necessarily improve students' misconceptions. Therefore, the computer simulation that the researchers use is a computer simulation developed based on misconception found in students.

This study was designed to determine the level of effectiveness of ALOP approach learning assisted by computer simulation to decrease the students' misconception on the material of optical instruments.

\section{Methods}

\subsection{Research design}

Mixed methods is a research method that involved collecting data quantitatively and qualitatively, uniting two forms of data, and use a different design, involving assumptions and theoretical frameworks [16]. The method is used to obtain a complete answer to the research problems. Quantitative research method in this study is used to determine the effectiveness of the application of ALOP assisted by computer simulation; quantitative data can be obtained directly based on the tests conducted before and after applying the ALOP learning. The acquisition of quantitative data is obtained using pre-test and post-test control group research design. On the other hand, the qualitative research method is used to determine the change in the conception process, particularly the students who experience misconceptions.

The embedded mixed methods were employed in this study. The embedded mixedmethod design was used for one or more forms of data (quantitative or qualitative or both) and the strategies are used simultaneously to analyse quantitative and qualitative data [16]. 


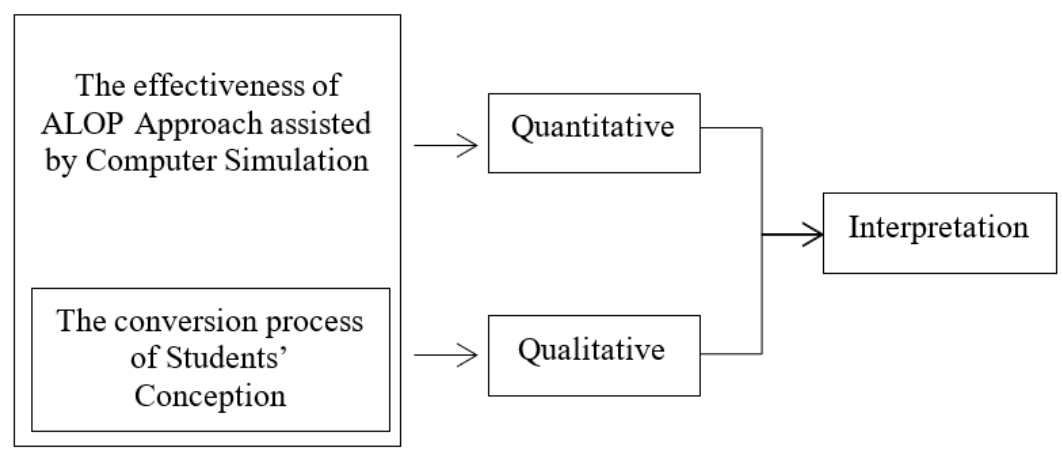

Fig. 1. Design of Embedded mixed methods

In Figure 1, it can be seen that the quantitative and qualitative data obtained simultaneously are used to interpret the results. Qualitative data are obtained during the pretest and post-test through quantitative data, which means that the quantitative data are obtained directly through the prior test, and after the application of computer simulation assisted by ALOP, whereas qualitative data are not obtained directly.

\subsection{Participants}

A research participant is defined as subjects who are involved in research activities to provide a response to the implementation given during the process of research, as well as to promote the goals of the study and take responsibility for their involvement. The researchers had considered various factors in choosing the participants; they were chosen from the class that experienced the most misconceptions linked to the material of optical instruments. The study involved two classes XI in one high school in Bandung, the experimental class and control class; each class consisted of 23 participants.

\subsection{Instruments}

The test instrument was in the form of diagnostic tests used to identify students' misconceptions. This diagnostic test was called the Four-Tier Optics and Photonics Test (FTOPT), which comprised 18 items. At the stage of preliminary study, researchers used a form of a two-tier test with the first-tier being in the form of multiple choices and the second tier was the reason for the answers in the first tier. At this second tier, the form was an open-ended test where students fill in the reasons for their choice of answers in the first tier. Furthermore, the responses from the second tier were selected to become the reason for the possible choices in the form of multiple choices in FTOPT. The test of the FTOPT development results is shown in Figure 2. 
14.1 Notice the ray diagram of image formation in the microscope.

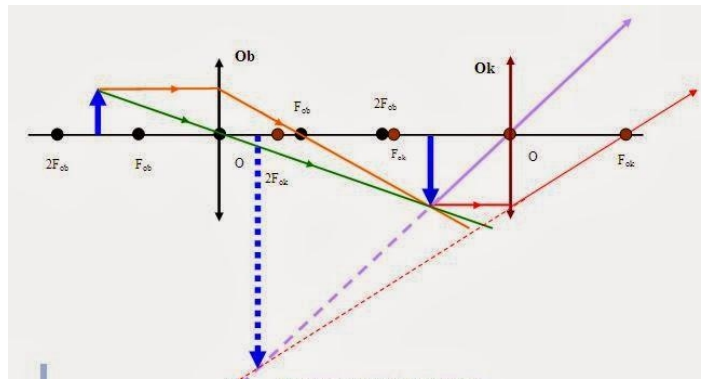

The diagram shows that the objects are placed in chamber II that is among $\mathrm{F}_{o b}$ and $2 \mathrm{~F}_{o b}$. The final image is located between the centre point $\mathrm{O}$ and ocular focal point $\mathrm{F}_{\text {ok }}$ (in the room I of ocular lens). The above diagram shows the observation with the eye....

Not accommodating, the image formed by the objective lens falls squarely in ocular focus.

Not accommodating, the image is virtual, inverted, and enlarged

Maximum accommodating, virtual image, inverted, and enlarged

Maximum accommodating, real image, inverted, enlarged

Accommodating, virtual image, inverted, enlarged. The image formed by the objective lens should fall squarely on the ocular focus.

14.2 Confidence level for Tier 14.1:

A.) Sure B.) Not Sure

The reason for Tier 14.1:

to obtain maximum magnification, it must be with a maximum accommodating eyes and the images by the objective lens should fall squarely on the ocular focus.

objects in chamber II will produce images with maximum magnification, if the eye accommodates maximum so that the final image is in the first chamber ocular lens

The final image resulted from ocular lens on the eye is not accommodating, according to the image that is virtual, inverted, and enlarged

The image formed by the objective lens must occur in the first chamber of the ocular lens. So that the final image formed by the ocular lens fell in a point near the eye of the observer.

14.4 Confidence level for Tier 14.3:

A.) Sure B.) Not Convinced

Fig. 2. Question number 14 on a four-tier diagnostic test

Figure 2 indicates a question number $14(\mathrm{Q} 14)$ of FTOPT. On the first tier (14.1) is a form of statement about the ray diagram of the formation of images on the microscope. On the second tier (14.2), the students are asked to choose the level of conviction to answer Question 14.1 in the form of "Sure" or "Not sure". On the third tier 
(14.3), the students chose the true reason for the answer to the first tier (14.1). Finally, on the fourth tier (14.4), the students are reselected to return to the level of confidence for the reason stated in the third-tier selection.

\subsection{ALOP Assisted by computer simulation}

ALOP has an active learning strategy namely, Interactive Lecture Demonstrations (ILDs). ILD is designed to engage students in the learning process, thus it alters the normally passive learning environment to become more active. Table 1 shows the eight steps of ILDs [17].

Table 1. Eight steps of Interactive Lecture Demonstration (ILD)

1. Teacher displays a demonstration in front of the class and demonstrates the concept in question-related phenomena.

2. Each student is asked to record a prediction on the prediction sheet, which will be collected, and can be identified with the student's name written on the top of the prediction sheet. (The students are told that this prediction will not be assessed, though some award will be given for attendance and participation at these ILD sessions.)

3. The students engage in small group discussions with one or two students who seat adjacent to each other.

4. Teacher acquires students' general prediction of the entire class.

5. The students record their predictions after the end of the discussion.

6. Students perform experiments related to the concept of the demonstrations that have been displayed by the teacher.

7. Some students describe experimental results and discuss them. Students can fill Sheet Results (the same as predictions sheets) that they can take to learn more.

8. Students review and discuss the results of experiments have been conducted.

The students are involved in understanding the conceptual demonstration based on observation, each student determines his/her individual prediction, and discuss their predictions in small groups. The students are given a sheet of prediction, then the teacher marks the students' predictions using different coloured pens. This is a brainstorming activity, and teachers emphasize to students that the prediction made is not necessarily true. One student is asked to read the predictions that have been made. If there is no student who voluntarily read his/her predictions (representing common misunderstanding) for the demonstration, the teacher gives motivation to students or randomly appoints some students to read their predictions. The purpose of this step is 
to help validate all of the predictions made by the students in the classroom. This activity can also be done by voting after all the predictions recorded. However, if the time is not sufficient, the teacher may skip this step and go to the next step.

In general, there are eight steps used to improve learning with a simple demonstration. Demonstrations are shown to the students, then the students make predictions based on their observations on the prediction sheet and collaborate with other students to discuss their predictions in a group. The teacher then asks some students to read the predictions they made. After that, the students perform the Real Experiment and compare the experimental results with their predictions, and representatives of students are asked to explain the phenomena observed in the classroom.

In this study, the implementation of ALOP learning assisted by computer simulation was addressed to the optical instrument topic. Computer simulations designed by the researcher were based on misconceptions found in the real setting. The computer simulations used for this study were Macromedia Flash, video, and animation. Furthermore, the computer simulations referred to as OpSi (Optical Simulation). Figure 3 is a display of OpSi used as a learning medium of ALOP.

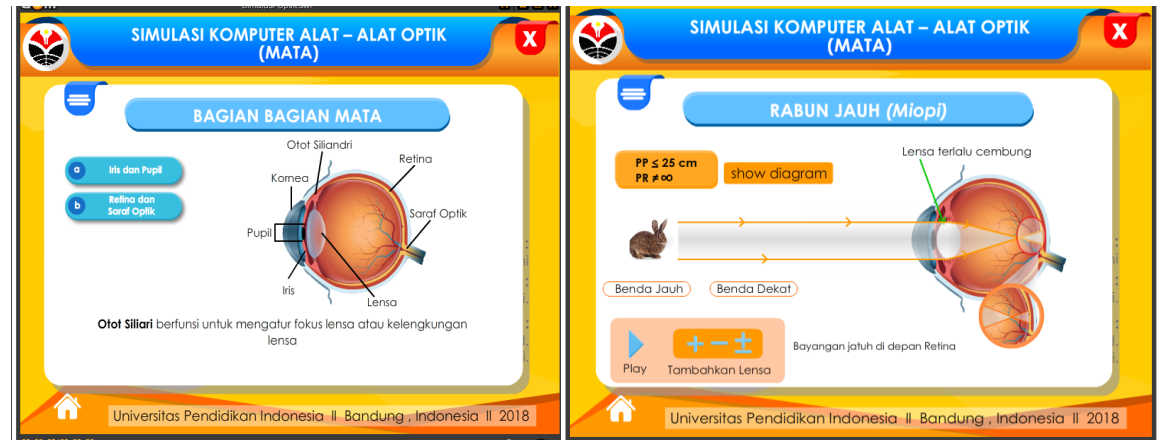

Fig. 3. Simulation of the sighting process of optical instruments

\section{$3 \quad$ Findings}

Figure 4 depicted the activity of students when implementing ALOP. The implementation results in the experimental class showed that the students simply enjoyed learning using the ALOP approach assisted by computer simulation as shown in Figure 4.

Kazis et al. [18] described the effect size as the "standard size of a change in the group or the difference in change between the two groups". Olejnik \& Algina [19] defined the size of the effect size "standard index" that estimated the independent variable of the sample sizes and quantified the magnitude of the differences between populations or the relationship between explanatory and response variables (p. 434). On the other hand, Tellez et al. [20] stated that the effect size can be used to determine the effectiveness of a treatment that is given to a particular group (experimental group). The effect size calculations using Glass's delta equation are presented in Table 2 . 

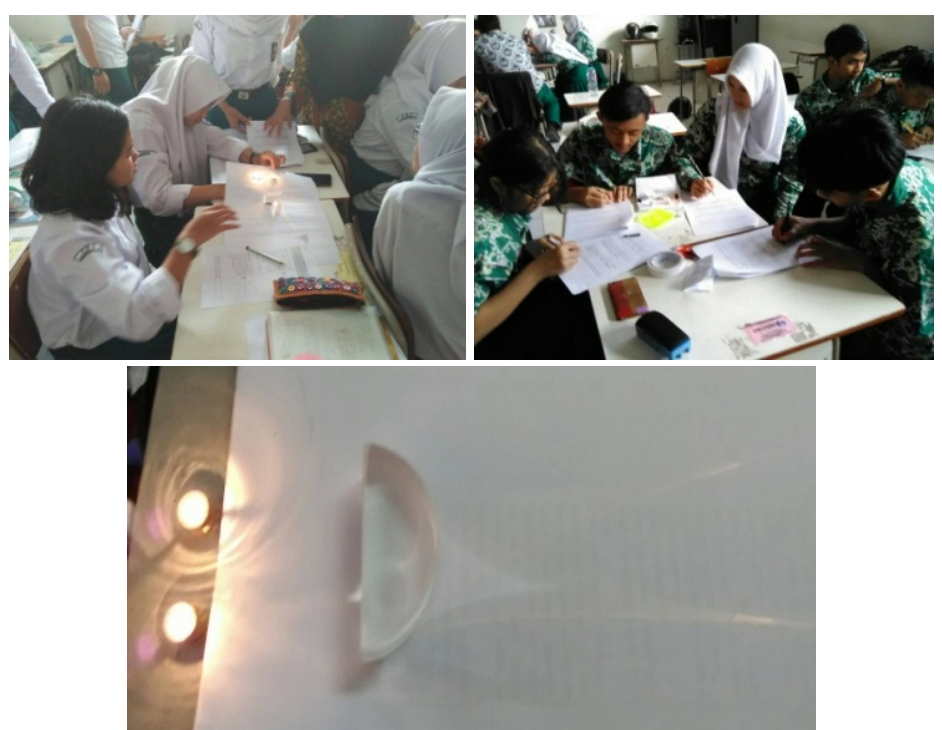

Fig. 4. Students' activities in ALOP approach learning

Table 2. Calculation of effect size with Glass's delta

\begin{tabular}{|c|c|c|c|}
\hline Class & Average (x) & Standard deviation (SD) & Glass's delta $(\Delta)$ \\
\hline Experiment & 62.32 & 10.36 & \multirow{2}{*}{0.81} \\
\hline Control & 54.35 & 9.87 & \\
\hline
\end{tabular}

Table 3. The distribution of students' conceptions on the pre-test and post-test experimental class

\begin{tabular}{|c|c|c|c|c|c|c|c|c|c|c|}
\hline \multirow{2}{*}{ No. } & \multicolumn{2}{|c|}{ MC } & \multicolumn{2}{|c|}{ SU } & \multicolumn{2}{c|}{ PU } & \multicolumn{2}{c|}{ NU } & \multicolumn{2}{c|}{ NC } \\
\cline { 2 - 11 } & $\begin{array}{c}\text { Pre- } \\
(f)\end{array}$ & $\begin{array}{c}\text { Post- } \\
(f)\end{array}$ & $\begin{array}{c}\text { Pre- } \\
(f)\end{array}$ & $\begin{array}{c}\text { Post- } \\
(f)\end{array}$ & Pre- $(\boldsymbol{f})$ & $\begin{array}{c}\text { Post- } \\
(\boldsymbol{f})\end{array}$ & $\begin{array}{c}\text { Pre- } \\
(f)\end{array}$ & $\begin{array}{c}\text { Post- } \\
(f)\end{array}$ & $\begin{array}{c}\text { Pre- } \\
(\boldsymbol{f})\end{array}$ & $\begin{array}{c}\text { Post- } \\
(f)\end{array}$ \\
\hline 1 & 2 & 0 & 4 & 19 & 14 & 4 & 3 & 0 & 0 & 0 \\
\hline 2 & 1 & 0 & 8 & 21 & 11 & 2 & 3 & 0 & 0 & 0 \\
\hline 3 & 13 & 4 & 0 & 16 & 0 & 3 & 10 & 0 & 0 & 0 \\
\hline 4 & 5 & 0 & 0 & 22 & 11 & 1 & 7 & 0 & 0 & 0 \\
\hline 5 & 5 & 0 & 2 & 0 & 13 & 23 & 3 & 0 & 0 & 0 \\
\hline 6 & 12 & 0 & 0 & 11 & 3 & 11 & 8 & 1 & 0 & 0 \\
\hline 7 & 11 & 10 & 0 & 4 & 4 & 8 & 8 & 1 & 0 & 0 \\
\hline 8 & 6 & 0 & 0 & 22 & 10 & 1 & 7 & 0 & 0 & 0 \\
\hline 9 & 12 & 5 & 1 & 5 & 10 & 12 & 0 & 1 & 0 & 0 \\
\hline 10 & 10 & 3 & 1 & 5 & 4 & 14 & 7 & 1 & 1 & 0 \\
\hline 11 & 12 & 1 & 0 & 13 & 7 & 9 & 4 & 0 & 0 & 0 \\
\hline 12 & 3 & 3 & 0 & 0 & 8 & 16 & 12 & 4 & 0 & 0 \\
\hline 13 & 4 & 1 & 2 & 15 & 10 & 5 & 6 & 1 & 1 & 1 \\
\hline 14 & 2 & 2 & 0 & 0 & 11 & 18 & 10 & 2 & 0 & 1 \\
\hline 15 & 4 & 1 & 0 & 1 & 8 & 18 & 10 & 2 & 1 & 1 \\
\hline 16 & 8 & 3 & 0 & 0 & 9 & 19 & 5 & 0 & 1 & 1 \\
\hline 17 & 6 & 2 & 0 & 9 & 11 & 5 & 6 & 1 & 0 & 1 \\
\hline 18 & 9 & 4 & 0 & 0 & 5 & 18 & 9 & 0 & 0 & 1 \\
\hline
\end{tabular}


Table 4. The percentage of misconceptions in the experimental class

\begin{tabular}{|c|c|c|c|c|}
\hline \multirow{2}{*}{ Question Number } & \multicolumn{2}{|c|}{ Experimental Class } & \multicolumn{2}{c|}{ Control Class } \\
\cline { 2 - 5 } & Pre-test (\%) & Post-test (\%) & Pre-test (\%) & Post-test (\%) \\
\hline 1 & 8.70 & 0.00 & 4.35 & 4.35 \\
\hline 2 & 4.35 & 0.00 & 4.35 & 0.00 \\
\hline 3 & 56.62 & 17.39 & 69.57 & 21.74 \\
\hline 4 & 21.74 & 0.00 & 17.39 & 4.35 \\
\hline 5 & 21.74 & 0.00 & 17.39 & 0.00 \\
\hline 6 & 52.17 & $0: 00$ & 47.83 & $0: 00$ \\
\hline 7 & 47.83 & 43.48 & 60.87 & 30.43 \\
\hline 8 & 26.09 & 0.00 & 21.74 & 21.74 \\
\hline 9 & 52.17 & 21.74 & 43.48 & 21.74 \\
\hline 10 & 43.48 & 13.04 & 34.78 & 30.43 \\
\hline 11 & 52.17 & 4.35 & 8.70 & 17.39 \\
\hline 12 & 13.04 & 13.04 & 4.35 & 8.70 \\
\hline 13 & 17.39 & 4.35 & 43.48 & 30.43 \\
\hline 14 & 8.70 & 8.70 & 34.78 & 30.43 \\
\hline 15 & 17.39 & 4.35 & 8.70 & 4.35 \\
\hline 16 & 34.78 & 3.04 & 26.09 & 30.43 \\
\hline 17 & 26.09 & 8.70 & 21.74 & 13.04 \\
\hline 18 & 39.13 & 17.39 & 34.78 & 8.70 \\
\hline Average & 30.19 & 9.42 & 28.02 & 15.46 \\
\hline & & & & \\
\hline
\end{tabular}

Misconceptions were identified using diagnostic tests such as four-tier test, Students who answered wrong on tier-one, confident in tier-two, wrong on tier-three, and believe in tier-four are identified as having misconceptions. The misconception is one of the five categories of students' conceptions, the other four are Sound Understanding (SU), Partial Understanding (PU), No Understanding (NU), and No Coding (NC). The profile of students' misconceptions obtained in this study was distinguished based on conception criteria shown in Table 3 . Table 4 shows the percentage of students in the experimental class who have misconceptions on every item.

\section{$4 \quad$ Result and Discussion}

Table 2 illustrates the calculation results of the effect size using Glass's delta equations. Referring to Table 2, the effect size was obtained by Glass's delta as much as 0.81 , which indicates a high interpretation. This means that the implementation of the ALOP approach assisted by computer simulation was effective to reduce the students' misconceptions on optical instrumentation topic. It is in line with a study by Fratiwi et al., [21] which suggested that learning assisted by computer simulations has a considerable impact on the reduction of the number of students' misconceptions on Newton's Law matter. Computer simulations may be used as the means of improving, motivating and interesting students' understanding of convinced measures [22-23]. Similarly, Faizin \& Samsudin [24] stated that teaching students using Virtual Analogy Simulation (VAS) can enhance students' conceptual understanding. Learning to use the analogy can reduce misconceptions rather than learning without analogical [25]. Based on these studies, the application of the ALOP approach aided by computer 
simulations was effective in reducing the number of students' misconceptions on the material of optical instruments.

Changes in students' conceptions before and after implementation were shown in Table 3. The number of students who have misconceptions tended to be reduced from pre-test to post-test. To illustrate, in Question Three (Q3), as many as 13 students believe that the farthest point and the nearest point of a myopic are smaller than the normal eye (MC). After implementing the approach, the students experience changes in the concept; the farthest point of myopic is indeed smaller than the normal eye. However, the nearest point of a myopic is the same as the normal eye, so that the post-test of SU category increases by 16 students. Some items, however, do not decrease in MC. For example, in Q12, a camera could form the object image, which is less than 2.5 meters from the camera, the distance of the lens. The students believe that the distance (s) from the object to the lens is 2.5 meters, the number of students $\mathrm{MC}$ in the pre-and post-test for Q12 remains the same, namely 13.04\%. It indicates that the ALOP approach assisted by computer simulation could not entirely overcome misconceptions. Another factor which is the students' willingness and passion for changing the misconceptions into scientific concepts is the biggest factor in the students' conceptual change.

Table 4 indicates the percentage of students who have misconceptions about each item. The average of misconceptions in the experimental class during pre-test is $30.19 \%$, most students have misconceptions when the pre-test was conducted on Q3 (56.62\%). They believe that the far point and the near point near the myopic is smaller than the normal eyes (MC). The least misconception is in Q2 (4.35\%), the students believe that the nearest point of a hypermetropia is further away from the normal eye so that the objects will be placed closer than $25 \mathrm{~cm}(\mathrm{MC})$. Q3 is a sub concept of the eye. Myopia is the difficulty to see distant objects so that the objects need to be placed very close to the eye. It has caused a far point, and a near point of myopia successively so PR $<\infty$ and $\mathrm{PP}<25 \mathrm{~cm}$ (MC). Students had the misconception that the nearest point of myopia is the eye, which is smaller than the nearest point of the normal eye $(\mathrm{PP}<25)$. Treatments were performed so that students acquired a scientific concept which demonstrated that those suffering from myopia has difficulty to see distant objects PR $<\infty$. Thus, the objects to be seen should be placed closer than $\infty$. However, the near point of myopia is supposed to be equal to the normal eye ( $\mathrm{PP}=25 \mathrm{~cm})$. One of the steps in the ALOP was making predictions; the students discussed with their other friends regarding predictions that has been made. Then, the students were asked to rewrite the prediction according to the results of the discussion. After that, the students tested the predictions using computer simulations as shown in Figure 5. 


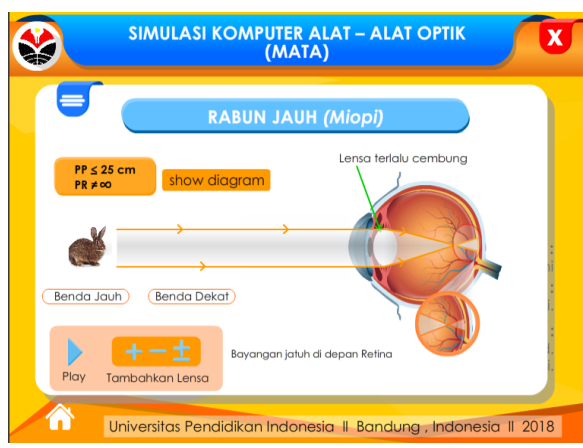

Fig. 5. a) Myopia sufferer sees distant objects

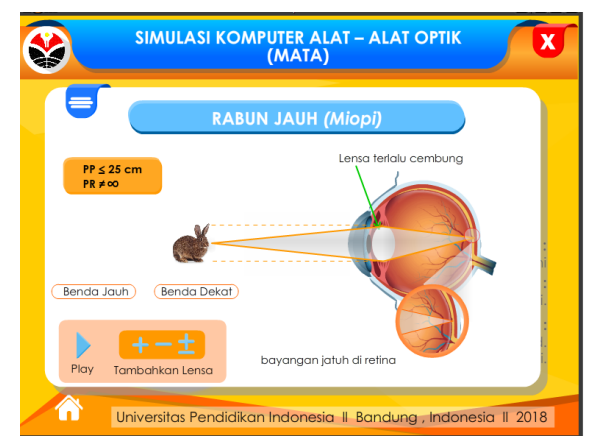

b) Myopia sufferer sees nearby objects

Using computer simulations for verification, students observed the image formation of distant objects on myopia and it was apparent that a shadow fell in front of the lens. Then someone who suffers from myopia saw that the nearby objects (click on the nearby objects then play), the students observed the process of image formation focused on the retina. The students discussed their observations and subsequently drew their own conclusions that the farthest point (PP) of myopia $\neq$ infinite, the near point of the eye near of myopia $\leq 25 \mathrm{~cm}$. The results of the post-test show that the MC3 of the experimental class has decreased by 39.13\% (Acceptable Change). Overall, the percentage of students who has misconceptions about the experimental class is reduced in the post-test. This can be seen in the average percentage of students who have misconceptions during the pre-test is $30.19 \%$ and the post-test is $9.42 \%$, so it can be calculated that the percentage change in the average misconceptions of the experimental class is $20.77 \%$. It was known that the average percentage change of misconceptions in the experimental class was larger than in the control class. As noted earlier that the experimental class implemented ALOP-approach learning assisted by computer simulation, while the control class used learning ALOP-approach without computer-aided simulation.

Analysis of the misconceptions in each item question (Q) along with the activities carried out by students to turn misconceptions into scientific concepts will be discussed next. The results of Q1 analysis indicate that $8.70 \%$ of students believe that someone who reads a book by keeping away the book as long as his arm has presbyopia eye abnormalities (MC1), then the ALOP learning assisted by the computer simulation was carried out. The students first observed a picture of someone reading at a distance as far as their arms. The students were asked to make predictions, "Is the person suffering from presbyopia or hypermetropia?". After that students discussed and proved predictions using computer simulations on the submenu of eye defects. The students arrived at a scientific concept that the person suffers from hypermetropia. The activity of keeping a book as far as his arm indicates that the nearest point of his eyes is farther away from the normal eyes. On the other hand, presbyopia had difficulty seeing close and distant objects, so that objects were placed not too nor too 
close. In the post-test, it the students' misconceptions could not be seen, while the SU category increased to 19 students.

The next question (Q2) discovered that around $4.35 \%$ of students believed that the near point of a hypermetropia was further away from the normal eye so that the objects were placed closer than $25 \mathrm{~cm}(\mathrm{MC} 2)$. Attempts to overcome the MC were made using the ALOP learning assisted by computer simulation. The students initially made predictions "To see things clearly, a hypermetropia put objects at a distance?" They then discussed their predictions with other members of the group and the students verified their predictions using computer simulations, Next, based on the phenomena they observed, the students concluded that hypermetropia is the difficulty seeing close objects so that objects should be placed at a distance farther than $25 \mathrm{~cm}(\mathrm{KI})$. In the post-test result, not one student has the misconceptions and the SU category increases to 21 students. Then the objects were placed closer than $25 \mathrm{~cm}$ (MC2). At the posttest result, none of the students had misconceptions and the SU category increased to 21 students.

Most students experienced a misconception during the pre-test which amounts to56.62\% in Q3 regarding the sub-concept of an eye. Myopic eyes are difficult to see distant objects. Thus, the object to be seen must be placed very close to the eye, due to the far point and the nearest point of the myopic eye are respectively PR $<\infty$ and PP $<25 \mathrm{~cm}$ (MC3). The students experienced a misconception that the nearest point of the myopic eye is smaller than the nearest point of the normal eye ( $\mathrm{PP}<25)$. The ALOP implementation assisted by computer simulation was carried out so that conceptual changes can occur, the myopic eyes were having difficulty seeing distant objects (PR $<\infty$ ), so the object to be seen had to be placed closer than $\infty$, but the nearest point of the myopic eyes was the same as the normal eyes $(\mathrm{PP}=25 \mathrm{~cm})$. Students answered confidently and correctly, so that no misconceptions could be found in the post-test, while the SU category had increased by $69.57 \%$.

The results of Q4's analysis found that during the pre-test none of the students included the category of understanding the whole concept (SU), most students were in the category of partial concept understanding (PU), and the rest included the $\mathrm{MC}$ and $\mathrm{NU}$ categories. In Q4, the students were asked to describe the formation of an image of a distant object in the right myopic and helper lens to help them. A total of $21.74 \%$ of the students believed that the image of a distant object was focused on the back of the lens (MC4). Efforts to overcome the misconceptions were carried out by ALOP assisted by a computer simulation. In the computer simulations, the students proved the predictions that they had made. The students observed the image of near objects and distant objects and it turned out that the image of a distant object fell in front of the lens, while a close object was right on the retina. After that, the students determined the helper lens for myopia eyes, on OpSi (Optic Simulation) there were three types of lenses namely positive, negative, and dual lenses. Students tried all three types of lenses, observe, and determine the right lens. The negative lens formed an image at the myopic far point, by which the eye lens was considered an object and was focused on the retina. The students answered correctly and were confident about the concept, so that in the post-test, MC decreased, while SU increased to $96 \%$. 
In Q5 as many as $21.74 \%$ of students answered incorrectly and believed that the accommodation capacity of the human eye was changing. The more the age increased, the ability of the eye to accommodate was getting better (MC5). The students made predictions, and then they discussed them with their friends, proving the predictions, until the students finally experienced conceptual change, namely the accommodation of the human eye decreased as the age increased. Thus, the misconception in the posttest was $0 \%$. Whereas for Q6, most respondents believed that the human eye could only see luminous objects, dark objects could not be seen by the eyes, the cat's eyes will glow in a dark room, in a dark room without light white objects would reflect light, the viewing process occurred because of light source produced by objects (MC6). The ALOP implementation was applied using a real experiment based on LKPD shaping objects by the lens, the students analysed the role of light. They were guided through questions such as. "What is the formation of images if the lights are off?", Then the students made predictions and discussed them with the group. Next, they tested the predictions by turning off the lights. Apparently, no image was formed. The students discussed and concluded that without light, the eyes cannot see objects around them, it does not mean that only luminous objects such as flashlights, stars and lights (objects that produce light), but other objects such as people, books, and chairs can be seen because there is light reflected by the object. Likewise, the cat's eyes will not glow without light. The misconception decreased by $52.17 \%$ (none of the students' misconceptions in the post-test), while SU increased by $47.82 \%$.

Question Q7 was. "If part of the lens is closed or divided into two parts, then "What is the image formed?" A total of $47.83 \%$ of the respondents answered with confidence that the shadow formed was half of the object (MC7). The student performed a real experiment based on student's worksheet shaping the lens. The student's worksheet consisted of predictions, questions, and work steps to test their predictions; one of the questions was "How are shadows produced when the flat surface of the lens is partially closed?". Then students proved their predictions, so as to obtain scientific concepts based on the phenomena they observe, the shadows formed were entirely witnessed but the closed part of the intensity was dimmer. Misconceptions were not fully resolved, in the MC post, the test decreased to $43 \%$, but the SU was increased to $17.39 \%$, PU $34.78 \%$, and NU decreased to $4.34 \%$, these conceptual changes were included as the acceptable change, although 10 respondents still had misconception on this matter.

A total of $26.09 \%$ students in Q8 believed that convex lenses were used as a loop because they had the property of spreading light so that the image of an object was enlarged from its original size (MC8). ALOP implementation was applied according to the eight steps of the ILD. The teacher demonstrated the experiment using an Optical KIT; the students observed that the light coming out of the lamp shone in all directions, the light that hits the lens surface, passed through the lens and the light passed through the lens formed a cone (collecting forms a focal point). The students concluded that the nature of the lens and the role of the convex lenses was to gather light (convergent). Thus, the misconception in the post-test was $0 \%$ and SU had a very large increase of $95.65 \%$. 
As many as $52.17 \%$ in Q9 students believed that the strength of the loops was not influenced by the medium in which the loop was used, meaning that the strength of the air and in the water was the same (MC9). Students were asked to make predictions, "What is the strength of the air and water?" The students discussed predictions they made, then they distinguished the results of the observations using loops in air and water. Each group discussed and presented the results of the students' analysis. Light passes through a different medium, when it passes through a different medium there is a change in direction (refraction). Air has a refractive index smaller than water, so the power of the lens in the water is smaller than in air. The MC category dropped to $21.73 \%$ and the SU category rose to $21.73 \%$.

In Q10 students believed that the pupils in the human eye had the same function as the diaphragm, namely regulating the intensity of the incoming light (MC10); as many as $43.48 \%$ of students experienced misconceptions in the pre-test. ALOP approach assisted by computer simulations was applied based on simulation student's worksheet. In the computer simulations, students could observe the function of the components in the eye and camera, then the students distinguished the function of the components in the camera and eyes. The iris in the human eye had the same function as the diaphragm, which regulates the intensity of the incoming light. While the pupils in the human eye have the same function as the aperture to regulate a large amount or the amount of light entering. Thus, in the post-test, the misconception dropped to $13.04 \%$. In Q11, the students were asked to determine the relationship between the lens' diameter and light intensity and the students experienced a misconception of $52.17 \%$. The larger the lens diameter of the camera, the more incoming light will be present (MC11). The ALOP approach assisted by computer simulations was implemented so that the students obtained the scientific concepts that the lens served to focus the light coming from objects so that the image fell on the camera film, while the one that regulated a lot of light was the aperture. Then the size of the lens did not affect much of the incoming light. In the post-test, the misconception became $4.35 \%$.

As many as $13.04 \%$ of the misconceptions were about calculating the distance of the lens on the camera. The camera had a focal length of $40 \mathrm{~mm}$. If the camera can form an image of an object that is not up to 2.5 meters from the camera, the known lens distance would be $2.5 \mathrm{~mm}$ (MC12). Problem Q12 was included in the subconcept of the camera. In this indicator, students were confused when they were trying to distinguish the distance of objects and the distance of the images. On the question, it was stated that the shadow of objects that are up to $2.5 \mathrm{~m}$ is the shadow distance (s'). Given an ALOP treatment assisted by computer simulation, the students identified the position of objects and shadows. At the post-test, the number of students with misconceptions was the same as the number prior to treatment, and the SU category did not increase, while students who understood partially (PU) rose to $69,57 \%$.

In Q13 students believed that "The microscope serves to see small objects to make them look bigger and clearer" (MC13). It was found that $17.39 \%$ of them experienced misconceptions. The students were given treatments using the ALOP approach through the question of how a microscope works so the students were directed towards the function of the microscope, for example, "Why do you see the xylem and phloem tissue in plants as thin as possible?" Students discussed and shared the results 
of their discussions with other groups. The students got the conclusion that the microscope served to observe microscopic objects, namely very small objects (bacteria and cells) rather than just small objects. As a result, the misconception dropped to $4.35 \%$. Students who understood the concept (SU) rose to $65.22 \%$.

The image formed by the objective lens fell precisely on the ocular lens which focuses on the use of microscopes with maximum accommodation eyes (MC14). As many as $8.70 \%$ of the students experienced misconception about the sub-concept of the microscope. In Q14, a picture of the shading of objects was made using a microscope with accommodating eyes. The existence of images should make it easier for the students to determine the shadow of the objects produced using the objective lens. During the treatment, students discussed the location of the objects and images on the lens; most students had difficulty understanding the formation of images by the lens. ALOP activities were more focused on drawing images and discussions so that they understood that for the maximum accommodation of the eyes, the image of the objects formed by the objective lenses fell in the space I of the ocular lens. After treatment, the number of students still experiencing misconception was reduced to $8.70 \%$. Because of the limitations of the simulation, the researchers did not include the misconception treatments for this topic, but other alternatives were used, namely PowerPoint and video. The SU category also did not increase, because students were still unsure of their answers, the PU category after the treatment rose to $78.26 \%$.

As many as $17.39 \%$ of the students in Q15 believed that for the eyes to accommodate, the image formed by the objective lens must fall right at the focal point of the ocular lens (MC15). After the treatment, the students understood that for the eye which was not accommodating, the images formed by the objective lens must fall right at the focal point of the ocular lens so that the shadow would be located at the far point of the eye $\left(\mathrm{s}^{\prime}=-\mathrm{PR}\right)$. During the post-test, the misconception decreased to $4.35 \%$, PU rose to $78.26 \%$ and students who did not understand the concept (NU) dropped to $8.69 \%$.

In Q16, 34.78\% of the students answered that the concave mirror and concave lens had the property of spreading light (MC16). The answer was wrong, concave mirrors have the property of collecting light (diverging) just like a convex lens, while a convex mirror is the same as a concave lens that is collecting light (convergent). In the post-test, the students who experienced this misconception (MC) dropped to $13.04 \%$ and the partial understanding category (PU) rose to $82.61 \%$.

All the lenses on the Galileo binoculars were convergent lenses that can collect light (MC17). In Q17, 26.09\% of students experienced misconceptions. They were given treatment so they understood that the Galileo binoculars used convex lenses as their objective and concave lenses as ocular. The increase in the SU category was $39.13 \%$.

In Q18, as many as 39.13\% of students believed that the focus distance (f) and lens strength (P) were inversely proportional and the graph was a linear line (MC18). The reason for the students to choose the answer was due to the relationship of $\mathrm{f}=1 / \mathrm{P}$. The ALOP treatment was performed using MS Excel to process and analyse the data. The students verified other students' predictions and answers so that the students obtained the knowledge that the lens's power function was the opposite of the lens's 
focal distance. A graph that shows the relationship between both is called exponential graphs. In the post-test, misconceptions dropped to $17.39 \%$, while the SU category increased to $78.26 \%$ and students who did not understand the concept experienced a drastic decline to just $39.13 \%$.

\section{Conclusion}

The implementation of Active Learning of Optics and Photonics (ALOP) assisted by computer simulations has been carried out to reduce students' misconceptions about the topic of optical instruments. A mixed-method was employed as a method to identify students' misconceptions in the form of the Four-Tier Optics and Photonics Test (FTOPT). The results of the study suggested that the misconceptions were found in the students' understanding of the concept of the eye, camera, loop, microscope, and telescope. The results of the students' misconception profile analysis also showed a decrease in the number of students' misconceptions in the experimental class, which was more noticeable than the control class. A significant decrease in the quantity of student misconception occurred in the experimental class that implemented the ALOP approach assisted by computer simulation. Therefore, the ALOP-approach assisted by computer simulation was effective to reduce students' misconceptions in the optical instrument material.

\section{Acknowledgements}

This work was financially supported by Hibah Penelitian Terapan Unggulan Perguruan Tinggi Research Grants, Ministry of Research, Technology and Higher Education of the Republic of Indonesia in the fiscal year 2019.

\section{$7 \quad$ References}

[1] Osman, E., BouJaoude, S. \& Hamdan, H. (2017). An investigation of lebanese G7-12 students' misconceptions and difficulties in genetics and their genetics literacy. International Journal of Science and Mathematics Education, 15(7), 1257-1280. https://doi.org/10.10 07/s10763-016-9743-9

[2] Liu, G. \& Fang, N. (2016). Student misconceptions about force and acceleration in physics and engineering mechanics education. International Journal of Engineering Education, 32(1), 19-29.

[3] Gurel, D., Eryilmaz, A., \& McDermott, L. (2015). A review and comparison of diagnostic instruments to identify students' misconception in science. Eurasia Journal of Mathematics, Science \& Technology Education, 11(5), 989-1008. https://doi.org/10.12973/eurasia. 2015.1369a

[4] Kaniawati, I., Fratiwi, N. J., Danawan, A., Suyana, I., Samsudin, A. \& Suhendi, E. (2019). Analyzing students' misconceptions about Newton's laws through Four-Tier Newtonian Test (FTNT). Journal of Turkish Science Education, 16(1), 110-122. https://doi.org/10.10 $\underline{63 / 1.4983967}$ 
[5] Samsudin, A., Fratiwi, N. J., Kaniawati, I., Suhendi, E., Hermita, N., Suhandi, A., Wibowo, F. C., Costu, B., Akbardin, J. \& Supriyatman S. (2017). Alleviating students' misconceptions about newton's first law through comparing PDEODE*E tasks and poe tasks: which is more effective? The Turkish Online Journal of Educational Technology, Special Issue for INTE 2017, 215-221. https://doi.org/10.1088/1742-6596/1280/5/052050

[6] Fratiwi, N. J., Kaniawati, I., Suhendi, E., Suyana, I. \& Samsudin, A. (2017). The trasnformation of two-tier test into four-tier test on Newton's laws concepts. AIP Conference Proceedings, 1848, 050011. https://doi.org/10.1063/1.4983967

[7] Michelet, S., Adam, J. M. \& Luengo, V. (2007). Adaptive learning scenarios for detection of misconceptions about electricity and remediation. International Journal of Emerging Technologies in Learning, 2(1), 1-5.

[8] Munawaroh, R. (2016). Identifikasi miskonsepsi siswa dan penyebabnya pada materi alat optik menggunakan three-tier multiple choice diagnostic test. Jurnal Inovasi Pendidikan Fisika, 5(2), 79-81. https://doi.org/10.26737/jipf.vli1.54

[9] Borgerding, L. A., Klein, V. A., Gosh R. \& Eibel, A. (2015). Student teachers' approaches to teaching biological evolution. Journal of Science Teacher Education, 71-92. https://doi. org/10.1007/s10972-015-9428-1

[10] Putri, L. O. L., Rahman, T. \& Priyandoko, D. (2017). Analyzing concepts mastery and misconceptions about evolution of biology major students. Journal of Physics: Conference Series, 812, 1-6. https://doi.org/10.1088/1742-6596/812/1/012083

[11] Kaniawati I, Samsudin A, Hasopa Y, Sutrisno A D and Suhendi E. (2016). The influence of using momentum and impulse computer simulation to senior high school students' concept mastery. Journal of Physics: Conference Series, 012060. https://doi.org/10.1088/17426596/739/1/012060

[12] Alborch, A., Pandiella, S. \& Benegas J. (2017). Active learning of geometrical optics in high school: the ALOP approach. Physics Education, 52, 1-9. https://doi.org/10.1088/13 61-6552/aa7cce

[13] Vavougios, D. \& Karakasidis, T. E. (2008). Application of ICT Technology in Physics Education: Teaching and Learning Elementary Oscillations with the Aid of Simulation Software. International Journal of Emerging Technologies in Learning, 3(2), 53-58.

[14] Sokoloff D R. (2017). Enhancing learning in lab and lecture with real time physics labs (RTP) and interactive lecture demonstrations (ILDs) using computer-based data acquisition tools, personal response systems (clickers) and interactive video analysis. Physics Teachers' Inventions Fair, 3-4.

[15] Banks J. (1999). Introduction to simulation In P. A. Farrington, H. B. Nembhard, D. T. Strurrock, \& G. W. Evans (Eds), Proceedings of the 1999 Winter Simulation Conference, Phoenix, AZ, New York, ACM Press, 7-13.

[16] Creswell, J. W. (2014). Research Design Qualitative, Quantitative and Mixed Methods Approaches. United States of America: SAGE Publications, Inc.

[17] Lakshminarayanan, V. (2011). Interactive lecture demonstrations, active learning, and the ALOP project. Proc. SPIE 8065, SPIE Eco-Photonics 2011: Sustainable Design, Manufacturing, and Engineering Workforce Education for a Green Future, 80650S. https://doi. org/10.1117/12.889508

[18] Kazis, L. E., Anderson, J. J. \& Meenan, R. F. (1989). Effect sizes for interpreting changes in health status. Med Care, 27(3), 78-89. https://doi.org/10.1097/00005650-198903001$\underline{00015}$

[19] Olejnik, S., \& Algina, J. (2000). Measures of effect size for comparative studies: Applications, interpretations, and limitations. Contemporary Educational Psychology, 25, 241-286. https://doi.org/10.1006/ceps.2000.1040 
[20] Tellez, A., Garcia, C. \& Verdugo, V. (2015). Effect size, confidence intervals and statistical power in psychological research. Psychology in Russia: State of the Art, 8(3), 27-46. https://doi.org/10.11621/pir.2015.0303

[21] Fratiwi, N. J., Samsudin, A. \& Coştu, B. (2018). Enhancing K-10 students' conceptions through computer simulations-aided PDEODE*E (CS-PDEODE*E) on Newton's laws. Jurnal Pendidikan IPA Indonesia, 7(2), 214-223. https://doi.org/10.15294/jpii.v7i2.14229

[22] Akpinar, E. \& Ergin, O. (2007). The Effect of Interactive Computer Animations Accompanied with Experiments on Grade 6th Students' Achievements and Attitudes toward Science. International Journal of Emerging Technologies in Learning, 2(2), 1-6.

[23] Wiana, W., Barliana, M. S. \& Riyanto, A. A. (2018). The Effectiveness of Using Interactive Multimedia Based on Motion Graphic in Concept Mastering Enhancement and Fashion Designing Skill in Digital Format. International Journal of Emerging Technologies in Learning, 13(2), 4-20. https://doi.org/10.3991/ijet.v13i02.7830

[24] Faizin, M. N. \& Samsudin A. (2018). The use of Virtual Analogy Simulation (VAS) in physics learning. Journal of Physics: Conference Series, 012048. https://doi.org/10.1088/ $\underline{1742-6596 / 1013 / 1 / 012048}$

[25] Ugur, G., Dilber, R., Senpolat, Y. \& Duzugen, B. (2012). The effect of analogy on students' understanding of direct current circuits and attitudes towards physics lessons. European Journal of Educational Research, 1(3), 211-223. https://doi.org/10.12973/eu-jer.1.3.2 $\underline{11}$

\section{Authors}

Ida Kaniawati, Sri Rahmadani, Nuzulira JaneusseFratiwi, Iyon Suyana, Agus Danawan, Achmad Samsudin and Endi Suhendi all work for Universitas Pendidikan Indonesia, at Bandung, West Java Province, in Indonesia.

Article submitted 2019-11-05. Resubmitted 2020-01-10. Final acceptance 2020-01-30. Final version published as submitted by the authors 